\title{
Alterações no sistema vestibulococlear decorrentes da exposição ao agrotóxico: revisão de literatura
}

\author{
Vestibulocochlear system alterations caused by exposure to \\ pesticides: a literature review
}

\author{
Daiane Körbes ${ }^{1}$, Aron Ferreira da Silveira² ${ }^{2}$ Miguel Ângelo Hyppolito ${ }^{3}$, Gisiane Munaro ${ }^{4}$
}

\begin{abstract}
RESUMO
Os agrotóxicos são amplamente utilizados no meio rural e sua larga utilização, desprovida de medidas de biossegurança apropriadas, vem provocando impactos potenciais tanto para a degradação ambiental quanto para o organismo humano, aumentando a incidência de intoxicações ocupacionais. O objetivo do presente estudo foi revisar e discutir a respeito da exposição aos agrotóxicos e sua influência na função e estrutura do sistema auditivo. Foram revisados periódicos nacionais e internacionais relevantes indexados no PubMed, Medline, Bireme e LILACS, assim como capítulos de livros e dissertações publicados no período entre 1987 e 2009. As pesquisas sugerem que a exposição, principalmente crônica, aos agrotóxicos induz a alterações funcionais no sistema vestibulococlear, manifestando ainda uma série de sinais e sintomas. Apesar da escassez de dados sobre a influência do organofosforado nas características morfológicas do aparelho auditivo, os estudos indicam que a exposição de caráter agudo aos agrotóxicos pode também ser responsável por alterações no sistema auditivo, caracterizadas por lesões estruturais na cóclea, principalmente nas células ciliadas externas.
\end{abstract}

Descritores: Praguicidas/efeitos adversos; Doenças do nervo vestibulococlear; Inseticidas organofosforados/efeitos adversos; Vestíbulo do labirinto/lesões

\section{INTRODUÇÃO}

Pesticidas do grupo dos organofosforados, compostos anticolinesterásicos que causam variado grau de toxicidade para o ser humano, são amplamente utilizados na agricultura há muitas décadas. Em razão do benefício do agrotóxico para o sucesso do plantio, o trabalhador tem a tendência de superestimar seus efeitos benéficos para o plantio, desconsiderando os malefícios à saúde em curto, médio e longo prazo. Embora um

Trabalho realizado no Programa de Pós-graduação em Distúrbios da Comunicação Humana da Universidade Federal de Santa Maria - UFSM - Santa Maria (RS), Brasil.

(1) Pós-graduanda (Mestrado) do Programa de Pós-graduação em Distúrbios da Comunicação Humana da Universidade Federal de Santa Maria - UFSM

- Santa Maria (RS), Brasil.

(2) Professor Titular do Departamento de Morfologia da Universidade Federal de Santa Maria - UFSM - Santa Maria (RS), Brasil.

(3) Doutor, Professor do Departamento de Oftalmologia, Otorrinolaringologia e Cirurgia de Cabeça e Pescoço da Faculdade de Medicina de Ribeirão Preto da Universidade de São Paulo - USP - Ribeirão Preto (SP), Brasil.

(4) Pós-graduanda (Mestrado) do Programa de Pós-graduação em Distúrbios da Comunicação Humana da Universidade Federal de Santa Maria - UFSM - Santa Maria (RS), Brasil.

Endereço para correspondência: Daiane Körbes. R. Miguel Ruschel, 153, Bairro Boa União, Estrela (RS), Brasil, CEP: 95880-000. E-mail: daianekorbes@gmail.com

Recebido em: 9/9/2009; Aceito em: 29/1/2010 grande número de pesticidas tenha sido descoberto no início do século, seus efeitos deletérios foram relatados somente a partir de 1932.

O uso indiscriminado acarreta um significativo número de intoxicações, agudas ou crônicas, por esse tipo de pesticida. A elevada aplicação de agentes tóxicos, sem o emprego dos cuidados necessários, tem contribuído para a degradação ambiental e para o aumento das intoxicações ocupacionais, tornando-se um dos principais problemas de saúde pública no meio rural brasileiro ${ }^{(1)}$.

Diversas pesquisas vêm sendo realizadas com o intuito de investigar os efeitos tóxicos de substâncias químicas no sistema auditivo e vestibular em decorrência da exposição ocupacional. Os agrotóxicos organofosforados atualmente compõem este grupo de substâncias consideradas de alta prioridade para pesquisas que investigam a ototoxicidade devido à exposição ocupacional, do qual já faziam parte os solventes industriais, metais pesados e outros compostos que comumente apresentam ação asfixiante, caso do monóxido de carbono e cianeto de hidrogênio ${ }^{(2-4)}$.

São do conhecimento científico as inúmeras alterações provocadas pela intoxicação por organofosforados no ser humano, no entanto, mais estudos se fazem necessários para um melhor entendimento da associação entre a exposição a agrotóxicos e a ocorrência de alterações especificamente nos sistemas e vias auditiva e vestibular. 
Dessa forma, a presente revisão pretende explorar e discutir a respeito da exposição dos trabalhadores rurais aos agrotóxicos e a influência deste agente na função e estrutura do sistema auditivo. Foi realizado um trabalho de revisão sistemática da literatura, com periódicos nacionais e internacionais pertinentes ao assunto abordado, acessados eletronicamente nas bases de dados PubMed, Medline, Bireme e LILACS, assim como capítulos de livros, dissertações e resumos de Congresso. Não houve restrição ao ano de publicação, sendo então analisados estudos com data de publicação compreendida entre o período de 1987 a 2009.

A pesquisa foi estruturada por meio dos termos: agrotóxicos, organofosforados, pesticidas, ototoxicidade, legislação, perda auditiva, sistema vestibular, ototoxicity e insecticides organophosphate.

Na busca, foram avaliadas e selecionadas apenas as pesquisas cujo título, resumo ou corpo do artigo mantivesse relação com o objetivo do presente estudo. Dessa forma, foram obtidas 44 publicações. Os diversos trabalhos encontrados foram filtrados de acordo com a consonância ao objetivo proposto pela presente revisão, bem como excluídos aqueles que se encontravam duplicados nas bases de dados. As informações de cada um dos artigos potencialmente relevantes para a revisão sistemática foram analisadas de acordo com o objetivo, métodos utilizados, resultados e importância científica na área de Audiologia.

Foram ainda excluídos da revisão aqueles estudos cujo enfoque era voltado às atividades da acetilcolinesterase, aos indicadores socioeconômicos, aos resíduos de pesticidas na dieta brasileira ou aos riscos dos pesticidas domésticos, totalizando a exclusão de 14 artigos indexados. Assim, a pesquisa foi composta por 16 artigos nacionais e 14 internacionais, cinco dissertações, três livros e dois resumos de Congresso.

\section{REVISÃO DE LITERATURA}

\section{Efeito dos agrotóxicos no organismo}

O trabalho agrícola no Brasil é uma atividade significativa do ponto de vista social e de negócio. Entretanto, a saúde do trabalhador desse setor nem sempre recebe a atenção necessária. Agregados ao trabalho agrícola podem-se encontrar ruídos de vários tipos, vibrações e produtos químicos específicos, como os agrotóxicos ${ }^{(5)}$.

O Brasil, embora apresente um parque industrial diversificado com grande inserção de empresas multinacionais, ainda possui sua economia baseada na agricultura, com seu potencial agrícola apontado como fator estimulante para o desenvolvimento de forte indústria de adubos e defensivos químicos para as lavouras ${ }^{(6)}$. Para atender à crescente demanda, agricultores têm sido estimulados a utilizar uma grande variedade de substâncias a fim de aumentar a produtividade e reduzir as perdas das safras. Esta ação tem levado ao uso indiscriminado de agrotóxicos, colocando em risco a saúde dos produtores, do meio ambiente e dos consumidores ${ }^{(7)}$.

A utilização dos agrotóxicos no meio rural brasileiro tem trazido uma série de consequências tanto para o ambiente como para a saúde do trabalhador rural. Em geral, essas consequências são condicionadas por fatores intrinsecamente relacionados, tais como o uso inadequado dessas substâncias, a alta toxicidade de certos produtos, a falta de utilização de equipamentos de proteção e a precariedade dos mecanismos de vigilância. Esse quadro é agravado pelo baixo nível socioeconômico e cultural da grande maioria desses trabalhadores ${ }^{(8)}$.

A Organização Mundial da Saúde (OMS) estima que a cada ano ocorra cerca de 3.000 .000 casos de intoxicação aguda por pesticidas, com 220.000 óbitos. A maioria destes incidentes ocorre nos países em desenvolvimento, como a África do Sul, Ásia, América Central e América do $\mathrm{Sul}^{(9)}$.

A intoxicação por agrotóxicos pode ocorrer por três vias: inalação, ingestão e dérmica ${ }^{(10-11)}$. No caso de envenenamento por inalação, os sintomas iniciais mais comuns são caracterizados por dores no tórax, dificuldade de respiração e dores de cabeça, aliadas à visão borrada e lacrimejante. Quando ingerido provoca náuseas, vômitos, diarréias e câimbras (efeitos iniciais mais comuns de envenenamento). Contrações e suor na pele são sintomas observados em caso de contato do produto com partes do corpo ${ }^{(11)}$.

De acordo com a literatura, as variáveis que determinam a toxicidade do organofosforado são o nível de exposição ao agrotóxico no meio-ambiente, a dose absorvida e o nível de depressão da acetilcolinesterase individual $l^{(9)}$.

Os inseticidas organofosforados são conhecidos por seu efeito anticolinesterásico. Estes agentes inibem a enzima acetilcolinesterase, responsável pela hidrólise da acetilcolina, levando a um acúmulo deste neurotransmissor nas sinapses nervosas ${ }^{(12)}$. Os sinais de intoxicação aguda estão associados à inibição da colinesterase, ou seja, aos efeitos colinérgicos exacerbados. A toxicidade crônica é relacionada a efeitos neurotóxicos ${ }^{(13)}$.

Em virtude do efeito inibidor das colinesterases, os pesticidas organofosforados podem ocasionar, em mamíferos, lacrimejamento, salivação, sudorese, diarréia, tremores e distúrbios cardiorrespiratórios. Estes últimos são decorrentes de broncoconstrição, aumento das secreções brônquicas e bradicardia, bem como de depressão do sistema nervoso central, sendo as principais causas de morbidade e mortalidade por tais produtos ${ }^{(14)}$.

Como sintomas da intoxicação aguda por inseticidas organofosforados, podem ser descritos suor, salivação, lacrimejamento, fraqueza, tontura, dores e cólicas abdominais, seguidos de vômitos, dificuldade respiratória, colapso, tremores musculares, convulsões e morte ${ }^{(15-16)}$. Os organofosforados causam também efeitos neurológicos retardados após a exposição aguda e como consequência da exposição crônica, incluindo confusão mental e fraqueza muscular ${ }^{(17)}$. A exposição crônica a estes compostos pode levar ao desenvolvimento de sintomas de depressão, um fator importante nos suicídios. Outros autores complementaram referindo que a exposição crônica ao agrotóxico está relacionada, entre outros, ao câncer, efeitos teratogênicos, neuropatias periféricas tardias e toxicidade reprodutiva ${ }^{(18)}$.

Em estudo realizado por alguns pesquisadores, a tontura foi o sintoma de maior destaque e, por se tratar de uma das expressões clínicas da exposição aos agrotóxicos, os estudiosos sugeriram que a mesma deve ser avaliada e detectada durante 
a anamnese específica do trabalhador rural, bem como devidamente investigada pelas equipes de saúde responsáveis pelo atendimento médico nas localidades ${ }^{(19)}$.

A elevada prevalência de quadros de intoxicação pelos agrotóxicos, tanto aguda como crônica, reflete a precariedade com que são realizadas as atividades de controle de pragas no campo, sem proteção por equipamentos se segurança e com uso indiscriminado de substâncias químicas prejudiciais ao meio ambiente, às espécies e ao homem. Os autores comentaram ainda que a frequência de sinais e sintomas provêem de uma ocorrência elevada de casos de contaminação humana por exposição simultânea a inúmeros produtos, utilizados geralmente na forma de coquetel, em curtos intervalos de reaplicação e sem a adoção das adequadas medidas de segurança ${ }^{(7)}$. O trabalhador agrícola, desconhecendo os riscos e os impactos negativos do uso de agrotóxicos na saúde, tende a supervalorizar seus benefícios para as plantações de culturas diversas, utilizando muitas vezes doses maiores que as necessárias, para obter melhores resultados agronômicos ${ }^{(20)}$.

\section{Ototoxicidade dos agrotóxicos}

A literatura sugere que os agrotóxicos organofosforados induzem a alterações do sistema auditivo e do sistema vestibular, tendo sido evidenciado ainda seu potencial neurotóxico na população exposta a este químico. Portanto, os efeitos dos agrotóxicos organofosforados sobre a saúde humana englobam uma variedade de sinais e sintomas, muito além da visibilidade clínica, necessitando de uma abordagem complexa à saúde, de forma a assegurar uma intervenção terapêutica e preventiva nas ações de saúde ambiental e do trabalhador ${ }^{(19)}$.

A configuração da perda auditiva provocada por substâncias químicas industriais, tais como pelos agrotóxicos, pode ser muito semelhante àquela observada em drogas ototóxicas como aminoglicosídeos e cisplatina, bem como àquela relacionada ao ruído. Os descritores, em geral, dessas desordens são muito semelhantes: perda auditiva neurossensorial para frequências de 3000 a 6000 Hz, com lesão principalmente em células ciliadas cocleares, sendo a alteração bilateral, simétrica e irreversível ${ }^{(21)}$.

Estudo realizado com agentes de saúde pública de Pernambuco demonstrou que a exposição crônica a inseticidas pode ser responsável pelo comprometimento da audição em nível periférico e central e, em caso de exposição combinada - ruído e inseticidas - ocorreria interação entre estes dois agentes, levando a uma potencialização da perda auditiva em nível periférico ${ }^{(22)}$.

Estudiosas investigaram a audição de 98 trabalhadores com idade média de 41,6 anos, submetidos à exposição crônica aos inseticidas organofosforados e piretróides com um tempo mínimo de três anos. Os sujeitos foram divididos em dois grupos: um grupo (47) sem exposição ao ruído e o outro (51) com exposição atual ou pregressa ao ruído. Constatou-se que $64 \%$ dos trabalhadores expostos somente aos inseticidas apresentaram perda auditiva, enquanto que para o grupo com exposição concomitante aos inseticidas e ruído, a incidência de alteração auditiva foi de $67 \%$. A partir desses resultados, as autoras concluíram que a exposição isolada aos inseticidas dos tipos organofosforados e piretróides induz ao dano auditivo periférico e o ruído é um fator que interage com os inseticidas, potencializando seus efeitos ototóxicos ${ }^{(23)}$.

As mesmas autoras anteriormente citadas, em nova publicação, referiram que as queixas de maior frequência observadas em seu estudo foram: irritação nos olhos $(54,1 \%)$, cefaléia $(44,9 \%)$, tonturas $(35,7 \%)$, náuseas e torpor $(16,3 \%)$. Já os sintomas mais referidos, relacionados ao sistema nervoso central (SNC) foram: dificuldades na compreensão da fala (46\%), dificuldade em lembrar alguns fatos (43\%), dificuldade em manter a atenção (24\%) e zumbido $(24 \%)^{(24)}$.

Um caso de perda auditiva após intoxicação aguda devida a dois tipos de organofosforados foi constatado por autores ${ }^{(25)}$. Em uma variação de oito a nove horas após a exposição, o indivíduo pesquisado apresentou visão turva e episódios graduais de náusea. No quarto dia após a exposição, referiu perda auditiva e tontura, sendo constatada perda auditiva bilateral profunda.

Um caso de perda auditiva súbita foi verificado nas frequências altas, bilateralmente, após a exposição aguda a um tipo de piretróide de uso doméstico. Contudo, houve regressão da perda auditiva posterior à desintoxicação mediante tratamento medicamentoso $^{(26)}$.

Pesquisadores realizaram um estudo na cidade de Cruz Alta, no Rio Grande do Sul, com indivíduos expostos a vários tipos de agrotóxicos, dentre eles os organofosforados. Foram determinados dois grupos de 42 homens cada, sendo um grupo constituído por sujeitos que trabalhavam no ramo da agricultura, com tempo médio de 15 anos, e outro grupo por trabalhadores sem exposição a agrotóxicos e sem história prévia de perda auditiva. Os resultados demonstraram que $60 \%$ (25) dos sujeitos expostos apresentaram limiares auditivos rebaixados, sendo a alteração do tipo neurossensorial bilateral em 23 deles. A maioria (23) dos trabalhadores com alteração nos limiares auditivos apresentou rebaixamento na faixa de frequências de 3000 a $6000 \mathrm{~Hz}$, no entanto, também foram encontradas alterações nas frequências de 1000, 2000 e $8000 \mathrm{~Hz}$. Dos 25 indivíduos com alteração nos limiares auditivos, $16 \%$ (4) estavam expostos somente a ruído e $84 \%$ (21) estavam expostos a ruído e agrotóxicos ${ }^{(27)}$.

Em outro estudo, realizado com trabalhadores rurais expostos aos agrotóxicos do tipo organofosforado e piretróide, constatou-se que $57 \%$ dos sujeitos apresentaram perda auditiva neurossensorial nas frequências altas ${ }^{(28)}$.

Em outra pesquisa com trabalhadores expostos a agrotóxicos organofosforados, o autor observou alta incidência de neuropatias periféricas e presença de perdas auditivas do tipo neurossensorial de grau leve a moderado nos trabalhadores expostos a agrotóxicos organofosforados ${ }^{(29)}$.

Os achados de alguns estudiosos corroboram com a pesquisa realizada pelo autor acima citado, uma vez que também foi verificada a ocorrência de perda auditiva periférica associada à exposição a plantações pulverizadas com inseticidas dos tipos piretróide e organofosforado em um grupo de agricultores em Nova York ${ }^{(30)}$.

Um estudo foi realizado com 18 trabalhadores rurais da cidade de Teresópolis, Rio de Janeiro, compreendidos numa faixa etária de 16 a 59 anos, que responderam a questionários 
e foram avaliados por meio de audiometria e vectoeletronistagmografia. Quando interrogados a respeito da interação entre o sistema de trabalho e a queixa de tontura, $72,25 \%$ dos entrevistados responderam que os produtos químicos que utilizam no trabalho afetam o equilíbrio, e ainda, 88,9\% deles acreditam que seu trabalho oferece risco à saúde. Os autores verificaram que $88,8 \%$ dos trabalhadores apresentaram alterações de equilíbrio corporal do tipo periférico irritativo e 38,8\% deles apresentaram perda auditiva do tipo neurossensorial, sendo que $22,22 \%$ apresentaram queda nas frequências de 6000 e $8000 \mathrm{~Hz}$, sugerindo que os agrotóxicos induzem alterações do sistema vestibulococlear através de uma intoxicação lenta e silenciosa $^{(19)}$.

O resultado do levantamento de publicações sobre o efeito dos agrotóxicos no sistema auditivo está apresentado no Quadro 1.

Pela imensa quantidade de agrotóxicos utilizada na agricultura e pela falta de um sistema de vigilância sanitária que acompanhe a audição dos trabalhadores periodicamente, tornase difícil prever qual o tipo de agrotóxico que pode causar dano auditivo no indivíduo. Sabe-se, no entanto, que grande parte desses produtos é neurotóxica, podendo afetar diferentes porções do sistema nervoso central e periférico ${ }^{(5)}$. Produtos neurotóxicos podem levar a problemas tão ou mais sérios do que a perda auditiva. Porém há evidências de que a perda auditiva possa ser uma manifestação precoce de intoxicação ${ }^{(3)}$.

Diversos autores alertaram sobre a questão da utilização de equipamentos de proteção individual, observando que a falta de uso dos equipamentos de segurança pode agravar ainda mais o quadro de alterações ${ }^{(19,24,27)}$.
Com relação especificamente ao labirinto vestibular, uma pesquisa foi realizada com 106 trabalhadores expostos ao tóxico clorpirifós, na qual foram realizados testes sensoriais e motores para avaliar os efeitos agudos da exposição a este agente. Os resultados do estudo indicaram que a influência da exposição pode ser observada primariamente na estabilidade postural com os olhos fechados e na condição de mudança de superfície, o que sugere um possível efeito subclínico envolvendo a propriocepção e o sistema vestibular. Demais aspectos verificados nos exames sensoriais e motores, tais como o olfato, acuidade visual, visão colorida, sensitividade vibrotátil, tremores, destreza manual e coordenação visuo-motora não apresentaram alterações ${ }^{(31)}$. Segundo a literatura, a acetilcolina é identificada como um neurotransmissor do controle eferente do labirinto vestibular ${ }^{(32)}$.

Pesquisas realizadas por japoneses revelaram a possibilidade de alterações vestibulares observadas com a análise postural nas vítimas de um envenenamento ocorrido em Tokyo, no Japão, pela substância Sarin, considerada um potencial anticolinesterásico ${ }^{(33)}$.

Em outro estudo, observou-se a associação entre a exposição ao agrotóxico, tanto aguda como crônica, e alterações posturais. As alterações mais evidentes foram observadas na condição de olhos fechados e alteração de superfície, indicando prejuízo nas respostas relacionadas à propriocepção e ao sistema vestibular ${ }^{(34)}$.

Além das alterações sintomáticas e funcionais descritas na literatura, recentemente pode também ser observada uma busca pela análise da ação do agrotóxico diretamente sobre as estruturas que desempenham funções primordiais no sistema

Quadro 1. Exposição ao agrotóxico e seus efeitos no sistema vestibulococlear

\begin{tabular}{|c|c|c|c|}
\hline Referência & Agente da exposição & Consequências & Comentários \\
\hline Harell, Shea e Ermett(24) & Organofosforado & $\begin{array}{l}\text { Perda auditiva, tontura e } \\
\text { náusea }\end{array}$ & $\begin{array}{l}\text { Perda auditiva bilateral profunda por } \\
\text { intoxicação aguda }\end{array}$ \\
\hline Ernest $^{(28)}$ & Organofosforado & Perda auditiva & $\begin{array}{l}\text { Perda auditiva neurossensorial de grau leve } \\
\text { a moderado }\end{array}$ \\
\hline Stefani, Matusuyama e Melo(25) & Piretróide & Perda auditiva & $\begin{array}{l}\text { Perda auditiva bilateral nas frequências } \\
\text { altas por intoxicação aguda }\end{array}$ \\
\hline Teixeira e Brandão ${ }^{(27)}$ & Organofosforado e piretróide & Perda auditiva & $\begin{array}{l}57 \% \text { com perda auditiva neurossensorial } \\
\text { nas frequências altas }\end{array}$ \\
\hline Beckett, Chamberlain e Hallman (29) & Organofosforado e piretróide & Perda auditiva & Perda auditiva periférica \\
\hline Teixeira, Augusto e Morata(22) & $\begin{array}{l}\text { Organofosforado, piretróide } \\
\text { e ruído }\end{array}$ & Perda auditiva & $\begin{array}{l}64 \% \text { expostos somente a inseticidas } \\
\text { com perda auditiva. } 67 \% \text { expostos } \\
\text { concomitantemente a inseticidas e ruído } \\
\text { com perda auditiva }\end{array}$ \\
\hline Teixeira, Augusto e Morata(23) & Organofosforado & $\begin{array}{l}\text { Cefaléia, tontura, zumbido } \\
\text { e náusea }\end{array}$ & $\begin{array}{l}\text { Queixa de cefaléia em } 44,9 \% \text {; de tontura em } \\
35,7 \% \text {; zumbido em } 24 \% \text {; náusea em 16,3\% }\end{array}$ \\
\hline Manjabosco, Morata e Marques ${ }^{(26)}$ & $\begin{array}{l}\text { Diversos tipos de agrotóxicos } \\
\text { e ruído }\end{array}$ & Perda auditiva & $\begin{array}{l}84 \% \text { expostos concomitantemente a } \\
\text { agrotóxicos e ruído com perda auditiva; } \\
16 \% \text { expostos somente a ruído com perda } \\
\text { auditiva }\end{array}$ \\
\hline Hoshino et al. ${ }^{(18)}$ & Organofosforado & $\begin{array}{l}\text { Alterações no equilíbrio } \\
\text { corporal e perda auditiva }\end{array}$ & $\begin{array}{l}88,8 \% \text { com síndrome vestibular periférica } \\
\text { irritativa; } 38,8 \% \text { com perda auditiva } \\
\text { neurossensorial }\end{array}$ \\
\hline
\end{tabular}


auditivo periférico (Figura 1). Pesquisadora realizou um estudo em cobaias para verificar os efeitos ototóxicos do organofosforado metamidofós nas estruturas da cóclea. A pesquisa envolveu cobaias albinas machos que foram intoxicadas via intraperitoneal, com doses diárias de $0,3 \mathrm{mg} / \mathrm{Kg}$ e 3,0 mg/Kg do agrotóxico Tamaron $\AA$, durante sete dias consecutivos, caracterizando uma exposição aguda. Foi verificado que as doses subletais de organofosforado metamidofós ocasionaram lesões morfológicas nas estruturas cocleares, sendo que as alterações ocorreram predominantemente nos estereocílios das células ciliadas externas e progrediram da espira 3 para a espira basal. A terceira fileira de estereocílios foi a primeira a ser atingida quando da intoxicação por organofosforado, ocorrendo progressão da lesão para a segunda e primeira fileiras de células. Dessa forma, o agrotóxico foi considerado um agente lesivo agudo das células ciliadas externas, uma vez que foram observadas alterações estruturais da cóclea, havendo ainda correlação entre a dosagem aplicada do agente e a quantidade de alterações observadas à microscopia eletrônica de varredura ${ }^{(35)}$.

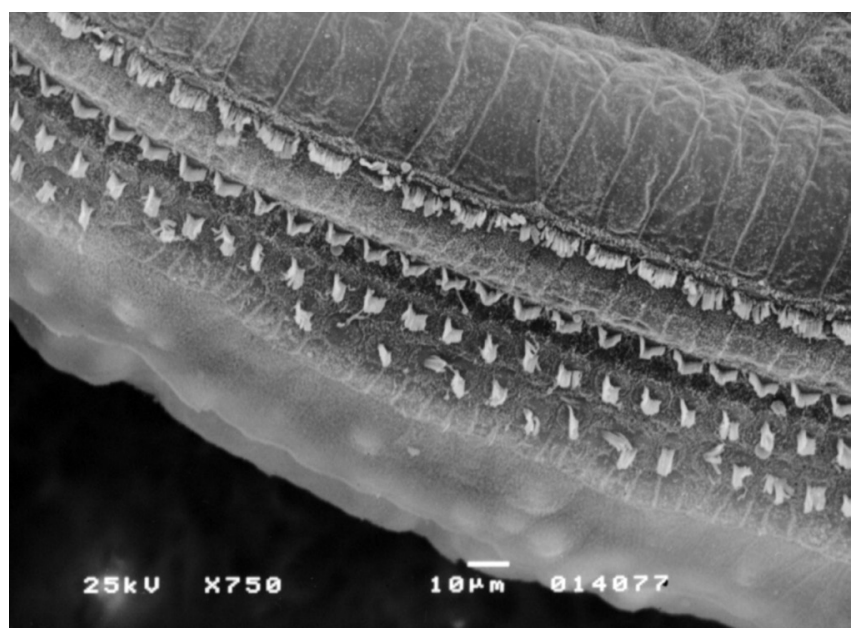

Figura 1. Aspectos morfológicos da cóclea de uma cobaia intoxicada pelo organofosforado, evidenciando lesão de estereocílios de CCE Fonte: ilustração cedida pela autora ${ }^{(35)}$

\section{DISCUSSÃO}

Apesar de se conhecer seu poder tóxico, o uso dos compostos organofosforados é ainda amplamente disseminado, principalmente nos países de terceiro mundo. Atualmente, o Brasil desponta como o maior consumidor de agrotóxicos da América Latina, respondendo por $50 \%$ da quantidade comercializada.

Dada a importância de instrumentos legais para o controle de substâncias perigosas, em julho de 1989 foi promulgada a chamada Lei dos Agrotóxicos (Lei Federal n 7.802/89), para a observância dos aspectos relacionados às substâncias químicas empregadas no controle de pragas e doenças da agricultura. Anteriormente a ela, a legislação que regulamentava o setor tinha como base um decreto promulgado em 55 anos antes, o Decreto ${ }^{\circ} 24.114$, de abril de $1934^{(36)}$.

A efetividade da lei, contudo, é prejudicada pela falta de recursos para fiscalização e pela ausência de autoridade para aplicar as penalidades e sanções, fruto também da permissi- vidade do Estado por não investirem em tecnologias menos agressivas $^{(37)}$. Esta pode ser uma das razões para que, apesar do conhecimento dos efeitos prejudiciais dos agrotóxicos, sua utilização permaneça em constante vigor.

Apesar da obrigatoriedade de receituário agronômico próprio, prescrito por profissionais legalmente habilitados, prevista no Artigo 13 da Lei dos Agrotóxicos, autores acreditam ainda há um número significativo de estabelecimentos que deixam de cumprir este termo. Tal fato ainda é agravado pela falha de vendedores na indicação dos agrotóxicos, o que poderia facilitar a utilização incorreta por dosagem e por cultura e, consequentemente, tornarem o trabalhador rural vulnerável à toxicidade dos pesticidas ${ }^{(12)}$.

A OMS estima que ocorram aproximadamente três milhões de envenenamentos humanos por pesticidas em todo o mundo ao longo de um ano, com mais de 220.000 mortes relatadas. No Brasil, a ocorrência de intoxicações por pesticidas do grupo dos organofosforados continua sendo alta, apesar da diminuição no seu uso em relação à década dos anos oitenta. Alguns autores ressaltam ainda que a dificuldade de acesso dos agricultores às unidades de saúde, o despreparo das equipes de saúde para relacionar os sintomas e problemas de saúde com a exposição aos pesticidas de forma particular, os diagnósticos incorretos e a escassez de laboratórios de monitoramento biológico são alguns dos fatores que influem na ocorrência de subdiagnóstico de intoxicação por agrotóxicos ${ }^{(38)}$.

Como descrito na literatura, a ação deletéria dos agrotóxicos sobre a saúde humana pode causar uma série de manifestações clínicas, como náuseas, tontura, fraqueza, falta de apetite, nervosismo, dores de cabeça, alergias, lesões renais e hepáticas, câncer e alterações genéticas. Em decorrência da inespecificidade dos sintomas relacionados à intoxicação, sendo estes comuns a múltiplos fatores etiológicos, torna-se difícil, muitas vezes, estabelecer a manipulação do organofosforado como o nexo causal.

Diversos estudos correlacionando perda auditiva com a exposição ao ruído têm sido vistos na literatura, no entanto, existem outros fatores de risco para a saúde auditiva que vêm sendo observados com frequência nos ambientes de trabalho. Ao se considerar perdas auditivas ocupacionais, é importante que se reconheça a potencialidade de outros agentes, como é o caso dos produtos químicos de efeito ototóxico ${ }^{(2-3,23,28,39)}$.

O trabalhador agrícola está exposto a vários agentes nocivos à saúde, incluindo ruídos, vibrações e produtos químicos específicos, como agrotóxicos. A ação destes agentes pode ser simultânea, favorecendo o comprometimento da audição. Os indivíduos que trabalhas em indústrias nas quais se faz necessária a exposição a elevados níveis de pressão sonora, tem um acompanhamento periódico no que diz respeito à saúde e principalmente audição, recebendo informações sobre o problema. Já os trabalhadores agrícolas, que estão em contato com diversos tipos de agrotóxicos, e, da mesma forma, podem sofrer a ação somatória de outros agentes nocivos, na grande maioria das vezes, não têm o mesmo acompanhamento. Pela influência destes fatores na audição, é possível que esses indivíduos sejam candidatos a apresentarem danos no sistema auditivo por estarem expostos a fatores de risco para a saúde $\operatorname{auditiva}^{(27)}$. 
Com relação ao sistema vestibulococlear, o efeito de agentes ototóxicos pode manifestar-se em lesões de células ciliadas externas, lesões do VIII par craniano, alterações no sistema vestibular e alterações no sistema nervoso central. A ação neurotóxica de algumas substâncias químicas encontradas nos ambientes de trabalho pode afetar não somente a audição e o equilíbrio, mas também o tronco cerebral e via auditivas centrais ${ }^{(40)}$. Há evidências de que a alteração auditiva possa ser uma manifestação precoce de intoxicação por organofosforados ${ }^{(27)}$.

Os aspectos relacionados ao controle dos agrotóxicos são diversos e envolvem questões políticas, sociais, econômicas e técnicas. A legislação é apenas um dos fatores essenciais para o controle dessas substâncias. Nesse sentido, a Lei dos Agrotóxicos se encontra em constante processo de implantação e vem passando por modificações e complementações, com a edição de novas portarias e decretos de regulamentação ${ }^{(36)}$.

Partindo de tal pressuposto, pode-se concluir que pesquisas baseadas nos indícios de potenciais danos e lesões em seres humanos e animais de laboratório devem continuar sendo realizadas, permitindo com que os efeitos ototóxicos dos pesticidas também se tornem um aspecto a ser incorporado na evolução da legislação.

\section{COMENTÁRIOS FINAIS}

Trabalhos de pesquisa que investiguem o ototoxicidade - cocleotoxicidade e vestibulotoxicidade - utilizando agrotóxicos permitem aprimorar os conhecimentos sobre anatomofisiologia da orelha interna e vias auditivas, sendo este o passo inicial para a descoberta de meios de prevenção e proteção mais eficientes do órgão de Corti.

Acredita-se que pesquisas que investiguem as alterações anatômicas das células ciliadas e demais estruturas do órgão de Corti, concomitantes à avaliação funcional do sistema auditivo, sejam a melhor forma para elucidar os mecanismos de lesão ototóxica dos agrotóxicos e permitir um melhor controle das alterações com medidas de prevenção da toxicidade da orelha interna.

Cabe ainda reforçar o fato de que, dada a relevância dos efeitos deletérios dos agrotóxicos na saúde humana, gerando uma série de sinais e sintomas, bem como impacto ambiental, se faz necessária uma ação tanto preventiva como terapêutica para assegurar a saúde do trabalhador rural, ao passo que novas portarias e regulamentações governamentais relativas à produção, comercialização e utilização dos agrotóxicos devam ser definidas e conduzidas com rigor para promoção e proteção da saúde e do meio ambiente.

\begin{abstract}
Pesticides are widely used in agriculture, and the widespread application of these agents, without the appropriate use of bio-security measures, has been causing potential impacts for environmental degradation, as well as for the human organism, increasing the incidence of occupational poisoning. The aim of the present study was to review the available literature and to carry out a discussion regarding pesticides exposure and its harmful effects on the auditory system's function and structure. Relevant national and international journals indexed in PubMed, Medline, Bireme and LILACS were reviewed, as well as book chapters and dissertations published between 1987 and 2009. The available data suggest that chronic exposure to pesticides lead to functional alterations in the vestibulocochlear system, as well as a series of signs and symptoms. In spite of the scarce data describing organophosphorus influence on morphological characteristics of the auditory system, the literature suggest that acute exposure to pesticides can also be responsible for auditory system alterations, characterized by structural lesions in the cochlea, mainly in outer hair cells.
\end{abstract}

Keywords: Pesticides/adverse effects; Vestibulocochlear nerve diseases; Insecticides, organophosphate/adverse effects; Vestibule, labyrinth/injuries

\title{
REFERÊNCIAS
}

1. Moraes AC. Contribuição para o estudo das intoxicações por carbamatos: o caso do chumbinho no Rio de Janeiro [dissertação]. Rio de Janeiro: Fundação Oswaldo Cruz, Escola Nacional de Saúde Pública; 1999.

2. Morata TC. Chemical exposure as a risk factor for hearing loss. J Occup Environ Med. 2003;45(7):676-82.

3. Azevedo AP. Efeito de produtos químicos e ruído na gênese de perda auditiva ocupacional [dissertação]. Rio de Janeiro: Fundação Oswaldo Cruz, Escola Nacional de Saúde Pública; 2004.

4. Mello AP, Waismann W. Exposição ocupacional ao ruído e químicos industriais e seus efeitos no sistema auditivo: revisão de literatura. Arq Int Otorrinolaringol. 2004;8(3):226-34.

5. Manjabosco CA. Perfil audiométrico de trabalhadores agrícolas. In: Morata TC, Zucki F, organizadores. Caminhos para a saúde auditiva: ambiental-ocupacional. São Paulo: Plexus; 2005. p. 53-66.
6. Barreira LP, Philippi Junior A. A problemática dos resíduos de embalagens de agrotóxicos no Brasil. In: XXVIII Congreso Interamericano de Ingeniaria Sanitaria y Ambiental; 2002; Cancun, Mexico.

7. Araújo AJ, Lima JS, Moreira JC, Jacob SC, Soares MO, Monteiro MC et al. Exposição múltipla a agrotóxicos e efeitos à saúde: estudo transversal em amostra de 102 trabalhadores rurais, Nova Friburgo, RJ. Ciênc Saúde Coletiva. 2007;12(1):115-30.

8. Oliveira-Silva JJ, Alves SR, Meyer A, Perez F, Sarcinelli PN, Mattos $\mathrm{RC}$, et al. Influência de fatores socioeconômicos na contaminação por agrotóxicos, Brasil. Rev Saúde Pública. 2001;35(2):130-5.

9. Jaga K, Dharmani C. Sources of exposure to and public health implications of organophosphate pesticides. Rev Panam Salud Pública. 2003;14(3):171-85. 
10. Lemus R, Abdelghani A. Chlorpyriphos: an unwelcome pesticide in our homes. Rev Environ Health. 2000;15(4):421-33.

11. Lima FJ, Marques PR, Nunes GS, Tanaka SM. Inseticida organofosforado metamidofós: aspectos toxicológicos e analíticos. Pesticidas: Rev Ecotoxicol e Meio Ambiente. 2001;11:17-34.

12. Bedor CN, Ramos LO, Rego MA, Pavão AC, Augusto LG. Avaliação e reflexos da comercialização e utilização de agrotóxicos na região do submédio do Vale do São Francisco. Rev Baiana Saúde Pública. 2007;31(1):68-76.

13. Cantarutti TF. Risco tóxico de resíduos de pesticidas em alimentos e toxicidade reprodutiva em ratos wistar [dissertação]. Curitiba: Universidade Federal do Paraná; 2005.

14. Ecobichon DJ, Joy RM. Pesticides and neurological diseases. In: Casarett LJ, Doull J. Toxicology the basic science of poisons. Boca Raton: CRC Press; 1991. p. 565-622.

15. Ames RG, Steeland K, Jenkins B, Chrislip D, Russo J. Chronic neurological sequelae to cholinesterase inhibition among agricultural pesticide applicators. Arch Environ Health. 1995;50(4):440-4.

16. Pires DX, Caldas ED, Recena MC. Intoxicações provocadas por agrotóxicos de uso agrícola na Microrregião de Dourados, Mato Grosso do Sul, Brasil, no período de 1992 a 2002. Cad Saúde Pública. 2005;21(3):804-14.

17. Alavanja MC, Hoppin JA, Kamel F. Health effects of chronic pesticide exposure: cancer and neurotoxicity. Annu Rev Public Health. 2004;25:155-97.

18. Caldas ED, Souza LC. Avaliação de risco crônico da ingestão de resíduos de pesticidas na dieta brasileira. Rev Saúde Pública. 2000;34(5):529-37.

19. Hoshino AC, Pacheco-Ferreira H, Taguchi CK, Tomita S, Miranda MF. Estudo da ototoxicidade em trabalhadores expostos a organofosforados. Rev Bras Otorrinolaringol. 2008;74(6):912-8.

20. Soares W, Almeida RM, Moro S. Trabalho rural e fatores de risco associados ao regime de uso de agrotóxicos em Minas Gerais, Brasil. Cad Saúde Pública. 2003;19(4):1117-27.

21. Morata TC, Little MB. Suggested guidelines for studying the combined effect of occupational exposure to noise and chemicals on hearing. Noise Health. 2002;4(14):73-87.

22. Teixeira CF. Exposição ocupacional aos inseticidas e seus efeitos na audição: a situação dos agentes de saúde pública que atuam em programas de controle de endemias vetoriais em Pernambuco [dissertação]. Recife: Fundação Oswaldo Cruz, Escola Nacional de Saúde Pública; 2000.

23. Teixeira CF, Giraldo Da Silva AL, Morata TC. Occupational exposure to insecticides and their effects on the auditorys. Noise Health. 2002;4(14):31-9.

24. Teixeira CF, Augusto LG, Morata CT. Saúde auditiva de trabalhadores expostos a ruído e inseticidas. Rev Saúde Pública. 2003;37(4):417-23.

25. Harell M, Shea JJ, Emmett JR. Bilateral sudden deafness following combined inseticide poisoning. Laryngoscope. 1978; 88(8 Pt 1):134851.
26. Stefani E, Matusuyama C, Melo RR. Ototoxicidade por inseticida doméstico: relato de um caso. In: $33^{\circ}$ Congresso Brasileiro de Otorrinolaringologia e $4^{\circ}$ Congresso Norte Nordeste de Otorrinolaringologia; Recife, 1996. Anais.

27. Manjabosco CA, Morata TC, Marques SJ. Perfil audiométrico de trabalhadores agrícolas. Arq Int Otorrinolaringol. 2004;8(4):284-95.

28. Teixeira CF, Brandão MF. Efeitos dos agrotóxicos no sistema auditivo dos trabalhadores rurais. Cad Inf Prev Acid. 1998;19:218.

29. Ernest K, Thomas M, Paulose M, Rupa V, Gnanamuthu C. Delayed effects of exposure to organophosphorus compounds. Indian J Med Res. 1995;101:81-4.

30. Beckett WS, Chamberlain D, Hallman E, May J, Hwang SA, Gomez $\mathrm{M}$, et al. Hearing conservation for farmers: source apportionment of occupational and environmental factors contributing to hearing loss. J Occup Environ Med. 2000;42(8):806-13.

31. Dick RB, Steenland K, Krieg EF, Hines CJ. Evaluation of acute sensorymotor effects and test sensitivity using termiticide workers exposed to chlorpyrifos. Neurotoxicol Teratol. 2001;23(4):381-93.

32. Ishiyama A, Lopez I, Wackym PA. Distribution of efferent cholinergic terminals and alpha-bungarotoxin binding to putative nicotinic acetylcholine receptors in the human vestibular end-organs. Laryngoscope. 1995;105(11):1167-72.

33. Yokoyama K, Araki S, Murata K, Nishikitani M, Okumura T, Ishimatsu S, et al. A preliminary study on delayed vestibulo-cerebellar effects of Tokyo Subway Sarin Poisoning in relation to gender difference: frequency analysis of postural sway. J Occup Environ Med. 1998;40(1):17-21.

34. Sack D, Linz R, Shukla C, Rice A, Bhattacharya A, Suskind R. Health status of pesticide applicators: postural stability assessments. J Occup Med. 1993;35(12):1196-202.

35. Körbes D. Toxicidade de agrotóxico organofosforado no sistema auditivo periférico de cobaias: estudo anatômico e funcional [dissertação]. Santa Maria: Universidade Federal de Santa Maria; 2009.

36. Garcia EG, Bussacos MA, Fischer FM. Impacto da legislação no registro de agrotóxicos de maior toxicidade no Brasil. Rev Saúde Publica. 2005;39(5):832-9.

37. Sobreira AE, Adissi PJ. Agrotóxicos: falsas premissas e debates. Cien Saúde Coletiva. 2003;8(4):985-90.

38. Silva JM, Novato-Silva E, Faria HP, Pinheiro TM. Agrotóxico e trabalho: uma combinação perigosa para a saúde do trabalhador rural. Cienc Saúde Coletiva. 2005;10(4):891-903.

39. Morata TC. Study of the effect of simultaneous exposure to noise and carbon disulfide on worker hearing. Scand Audiol. 1989;18(1):53-8.

40. Bernardi AP, organizador. Conhecimentos essenciais para atuar bem em empresas: audiologia ocupacional. São José dos Campos: Pulso; 2003. Testes utilizados na avaliação de trabalhadores expostos a níveis de pressão sonora elevados e solventes; p. 67-80. 